Journal of Biotechnology and Strategic Health Research

Olgu Sunumu / Case Report

http://dergipark.org.tr/tr/pub/bshr

\title{
Kontakt Lens Kullanan Bir Hastada Bacillus cereus' a Bağlı Keratit Olgusu
}

\author{
A Case of Keratitis Due to Bacillus cereus in a Patient Using Contact Lens
}

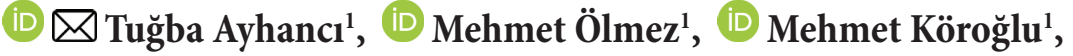 \\ (D) Mustafa Altındiș ${ }^{1}$, (D) Sibel Alişan ${ }^{3}$
}

${ }^{1}$ Sakarya Üniversitesi Tip Fakültesi, Tibbi Mikrobiyoloji Anabilim Dalı, Sakarya

${ }^{2}$ Sakarya Üniversitesi Tip Fakültesi, Göz Hastalıkları Anabilim Dalı, Sakarya

ORCID ID: Mustafa Altindiş 0000-0003-0411-9669, Mehmet Köroğlu 0000-0001-8101-1104, Tuğba Ayhanci 0000-0002-2115-6261

Mehmet Ölmez 0000-0002-0149-4271, Sibel Alişan 0000-0002-6780-11

^Sorumlu Yazar / Corresponding Author: Arș. Gör. Tuğba Ayhancı, e-posta / e-mail: tugba.ayhanci@hotmail.com

Geliş Tarihi / Received : 17-12-2020 Kabul Tarihi / Accepted: 18-04-2020 Yayın Tarihi / Online Published: 30-04-2020

Atıf Gösterimi/How to Cite: Ayhancı T., Ölmez M., Köroğlu M., Altındiş M., Alişan S. Kontakt Lens Kullanan Bir Hastada Bacillus cereus'

a Bağlı Keratit Olgusu, J Biotechnol and Strategic Health Res. 2020;4(1):56-60

$\ddot{\mathrm{O} z}$

Bacillus cereus hava, su ve toprakta bol miktarda bulunan, sporlu, aerobik ya da fakültatif anaerobik olabilen Gram pozitif basildir. Bakteriyel keratit, korneanın bakteriyel enfeksiyonu sonucu gelişen inflamasyon ve doku yıkımı ile karakterize oküler enfeksiyon hastalığıdır. B.cereus, çok nadiren keratit etkeni olmakla beraber gözde yıkıcı etkiler oluşturarak hızla görme kaybına neden olan enfeksiyonlara yol açabilmektedir. Burada kontakt lens kullanımı, oküler yüzey hastalıkları, kornea travması, immünosüpresif ilaçların kullanımı, postoküler cerrahi ve kornea grefti bakteriyel keratit için risk faktörlerini oluşturmaktadır. $\mathrm{Bu}$ vaka sunumunda B.cereus ile kontamine olmuş kontakt lens kullanan hastada gerçekleşen keratit olgusu sunulmaktadır. Literatür verileri incelendiğinde Türkiye'den bildirilen B.cereus kaynaklı ilk keratit olgusu olduğu düşünülmektedir.

Hastanemizin göz polikliniğine sol gözünde batma hissi, ağrı ve şişlik nedeni ile başvuran ve kontakt lens kullanan 28 yaşındaki kadın hastanın gece yatarken lensini çıkarmadığı ve yaklaşık bir ay önce kontakt lens gözünde bulunduğu halde darp edildiği öğrenildi. Lens solüsyonu ve göz sürüntü materyali kültür amacı ile mikrobiyoloji laboratuvarına gönderildi. Ertesi gün üreyen bakterinin kütle spektrometrisi ile identifikasyonu yapılarak bakterinin B.cereus olduğu saptandı. Topikal moksifloksasin göz damlası (5X1), saat başı suni gözyaşı ve göz pomadı (2X1) ile 10 günlük tedavi sonrası hastada keratitin tamamen iyileştiği saptand.

Anahtar Bacillus cereus, keratit, kontakt lens, travma

Kelimeler

Abstract

Bacillus cereus is a Gram-positive bacillus that is abundant in air, water and soil, which can be spore, aerobic or facultative anaerobic. Bacterial keratitis is a disease of ocular infection characterized by inflammation and tissue destruction caused by bacterial infection of the cornea. Although B.cereus is rarely a causative agent of keratitis, it can cause destructive effects in the eye and cause infections that rapidly cause vision loss. Here, contact lens wear, ocular surface diseases, corneal trauma, use of immunosuppressive drugs, postocular surgery and corneal graft are risk factors for bacterial keratitis. This case report presents a case of keratitis in a patient using contact lenses contaminated with B.cereus. Data from the literature are believed to be the first reported B.cereus induced keratitis cases from Turkey are examined.

It was learned that a 28-year-old female patient who applied to our ophthalmology clinic with stinging sensation, pain and swelling in her left eye did not remove her lens at night and was beaten although she was in the contact lens eye about a month ago. Lens solution and eye swab material were sent to microbiology laboratory for culture. The next day, the bacteria were identified by mass spectrometry and the bacteria were identified as B.cereus. After 10 days of treatment with topical moxifloxacin eye drops (5X1), artificial tears per hour and eye pomade (2X1), keratitis was completely healed.

Keywords Bacillus cereus, bacterial keratitis, contact lens, trauma 


\section{GIIRIŞ}

Bacillus cinsi bakteriler hava, su ve toprakta bol miktarda bulunan, sporlu, aerobik ya da fakültatif anaerobik olabilen Gram pozitif basillerdir. Bacillus cereus, Bacillus subtilis, Bacillus anthracis, Bacillus licheniformis ve Bacillus thuringiensis en çok bilinen türler olmakla beraber yaklaşık olarak 50 türü bulunmaktadır ${ }^{1}$ Çevrede yaygın olarak bulunan çoğu tür saprofittir. Ancak firsatçı ve zorunlu patojen türleri de bulunmaktadır. En çok bilinen türlerden olan ve şarbon etkeni olarak bilinen $B$. anthracis A grubu biyoterörizm ajanıdır. Klinik olarak kutanöz, gastrointestinal ve yüksek oranda mortal olan solunum sistemi şarbonu olmak üzere 3 formda görülebilmektedir ${ }^{2}$. Gastrointestinal sistem florasinda bulunan B. subtilis'in probiyotik preperatlarının birçok hastalıkta yararlı olduğu düşünülmektedir ${ }^{3,4}$. B. subtilis, patojen olmayan bir tür olarak bilinmesine rağmen iyi fırınlanmamış ürünlerin tüketilmesine bağlı olarak besin zehirlenmesi yaptığg bilinmektedir3. B. licheniformis, B. subtilis grubunda yer alıp uzun yıllardan beri tıbbi destek ürünü olarak kullanılmaktadır ${ }^{5}$. Fakat kontamine pişmiş et ve sebze tüketen insanlar için toksijeniteye ve gıda zehirlenmelerine neden olmaktadır. Ayrıca insanlarda septisemi, peritonit, korneal ülser ve göz enfeksiyonlarından da sorumlu tutulmaktadir ${ }^{6}$. B. thuringiensis ise dünya çapında ormancılık ve tarım alanında biyopestisit olarak kullanılmaktadır ${ }^{7}$. Kontaminasyon durumunda bu türde $B$. licheniformis gibi besin zehirlenmesi, periodontitis, korneal ülser, yara ve yanık enfeksiyonu yapabilmektedir ${ }^{8}$.

B.cereus, diğer Bacillus türleri gibi toprak ve bitki örtüsü üzerinde yaygın olarak bulunmaktadır ${ }^{9}$ Bu nedenle klinik örneklerde izole edildiğinde genellikle kontaminant olarak yorumlanmaktadır ${ }^{10}$. Fakat düşük patojenitesine rağmen nekrotizan ekzotoksin, emetik toksin, hemolizin, lesitinaz ve proteaz gibi toksin ve enzimleri sayesinde besin zehirlenmesi, yanık, yara ve cilt enfeksiyonları, menenjit, alt solunum yolu enfeksiyonları, endokardit, bakteriyemi, sepsis, posttravmatik endoftalmit ve keratit gibi göz enfeksiyonlarına neden olabilmektedir ${ }^{9}$. Bakterinin en sık yaptığı enfeksiyon, labil ve stabil toksinleri ile oluşturduğu emetik veya diyareli olabilen besin zehirlenmesidir. Bunun yanı sıra çok nadir vakalarda gözde oluşturduğu yıkıcı etkileri ile önemli bir oküler patojen olarak bilinmektedir ve bu özelliği ile cins içerisinde dikkat çekmektedir ${ }^{1,11}$. Literatürde, az sayıda yayında keratit etkeni olarak bildirilmiştir. Literatür verileri incelendiğinde, Türkiyede sunulan bir rapor bulunmadığı görülmüştür. Yayınlarda bakterinin bitkisel veya metalik madde ile penetran hasar sonrası ciddi posttravmatik keratit ve endoftalmi ile ilişkili olduğu bulunmuştur. Yine immün sistemi baskılanmış hastalarda kornea enfeksiyonu oluşturduğu raporlar arasındadır ${ }^{12}$. Kontakt lens kullanımı, oküler yüzey hastalıkları, kornea travması, immünosüpresif ilaçların kullanımı, postoküler cerrahi ve kornea grefti risk faktörlerini oluşturmaktadır. B.cereus dışında B.brevis, B.coagulans, B.subtilis, B.licheniformis B.laterosporus ve B.thuringiensis gibi türler de keratit ile ilişkili bulunmuştur.

Bu yazıda, B.cereus ile kontamine olmuş kontakt lens kullanan hastada gerçekleşen keratit olgusu sunulmaktadır.

\section{OLGU}

Kontakt lens kullanım öyküsü olan 28 yaşındaki kadın hasta sol gözünde batma hissi, ağrı ve şişlik nedeni ile hastanemiz göz polikliniğine başvurmuştur. Hastanın gece yatarken lensini çıkarmadığı ve yaklaşık bir ay önce kontakt lens gözünde bulunduğu sırada darp edildiği öğrenildi. Klinik muayenede; sol gözde korneal epitel hücre defekti ve üst kapakta ödem gözlendi. Kullanılan lens solüsyonu ve göz sürüntü materyali kültür amacı ile mikrobiyoloji laboratuvarına gönderildi. Ampirik tedavi olarak topikal moksifloksasin (5X1), saat başı suni gözyaşı ve pomad (2X1) başlandı. Gönderilen lens solüsyonu ve göz sürüntüsü materyali mikrobiyoloji laboratuvarında bakteriyolojik açıdan değerlendirilmesi amacıyla işleme alındı. Örneğin mikroskobik incelemesinde Gram pozitif basiller görüldü. Hasta örneği kanlı agar, çikolata agar ve eosin metilen mavisi (EMB) agara ekilerek, $35-37^{\circ} \mathrm{C}$ 'de bir gece inkübe edildi. Ertesi gün kültür plaklarında büyük, beta 
hemoliz yapan R tipi koloniler ürediği gözlendi (Şekil). İzole edilen bakterinin identifikasyonu kütle spektrometrisi (VITEK MS, bioMerieux, Fransa) ile yapildı ve izolat B.cereus olarak tanımlandi.

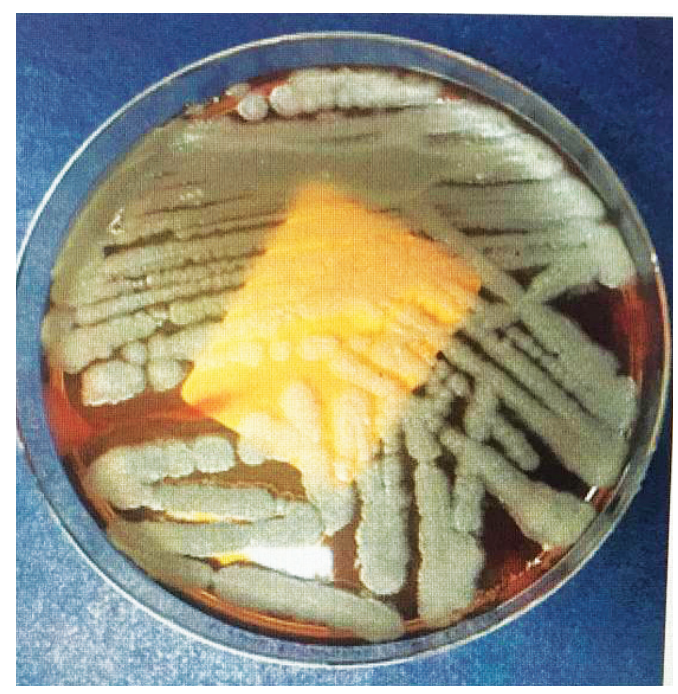

Şekil. B.cereus beta hemofiz yapan R tipi koloni morfolojisi

Üreyen bakterinin antibiyotik duyarllık testi E-test yöntemi ile yapılarak CLSI (M45-A2) kriterlerine göre yorumland. Test sonucunda bakterinin ampisilin ve seftazidime dirençli iken imipenem, siprofloksasin ve vankomisine duyarlı olduğu saptandı. Uygulanan ampirik tedaviye 10 gün süre ile devam edildi. Hastanın takip eden muayenelerinde, epitel hücre defektinde üç gün sonra azalma olduğu gözlendi. Tedavi bitiminde keratit bulgularının tamamen gerilediği ve iyileştiği saptandı.

\section{TARTIŞMA}

Bakteriyel keratit, korneanın bakteriyel enfeksiyonu sonucu gelişen inflamasyon ve doku yıkımı ile karakterize oküler enfeksiyon hastalığıdır. Global olarak katarakttan sonra görme kaybının ikinci en sık nedeni olarak bilinmektedir ${ }^{13}$. Günümüzde, özellikle gelişmiş ülkelerde kontakt lenslerin yaygın kullanımı kontakt lens ile ilişkili keratit insidansını önemli ölçüde arttırmıştır. Kontakt lens kullanımı, oküler yüzey hastalıkları, kornea travması, immünosüpresif ilaçların kullanımı, oküler cerrahi sonrası ve kornea grefti bakteriyel keratitin etiyolojisi ve patogenezini de etkilemektedir. Ayrıca bakteriyel keratit spektrumu coğrafi ve iklimsel faktörlerden etkilenebilir. Popülasyonlar arasında keratit profilinde birçok farklılık olduğu görülmüştür ${ }^{14}$. En sık karşılaşılan keratit etkenleri ise Stafilokok türleri, Streptococcus pneumoniae ve Pseudomanas aeruginosa'd $r^{13}$.

B.cereus, keratit, endoftalmit ve korneal ülserlerin nadir fakat önemli bir nedenidir. Gözü etkileyen en virülan organizmalardan biri olarak bilinmektedir. Travma, cerrahi işlem ya da kontakt lens kullanımına bağlı bakteri sporları ile kontaminasyon sonrasında gözde yıkıcı etkiler oluşturarak hızla görme kaybına neden olabilmektedir ${ }^{1}$. Bu nedenle identifikasyon ve antibiyotik duyarllık testlerinin zaman kaybetmeden yapılması görme kaybının önlenmesi için büyük önem taşımaktadır. B.cereus nedenli keratit veya diğer göz enfeksiyonları bakteri ile kontamine olmuş lens bakım sistemleri ile ilişkili bulunmaktadır ${ }^{15}$. Literatürde, asemptomatik hastaların yaklaşık olarak \%7’sinin kontakt lens bakım ürünlerinde Bacillus türlerinin bulunduğu raporlanmıştır. Bakteri sıcağa ve kimyasal dezenfektanlara dirençli sporları sayesinde lens bakım ürünlerinde canlı kalabilmektedir ${ }^{16}$. Bu nedenle, kontaminasyon sonrası organizmanın tavsiye edilen lens bakım teknikleri kullanılarak sistemden yok edilmesi güç hatta imkansız olabilmektedir.

Literatürde, kontakt lens kullanımına bağlı ilk keratit olgusu Antonio Pinna ve ark. ${ }^{1}$ tarafından 2000 yılında bildirilmiştir. Bu çalışmada ticari lens bakım sistemleri içerisinde yer alan hidrojen peroksit-katalaz, polyquaternium-1 ve PAPB çözeltilerinin üretici talimatlarına göre önerilen minimum süre boyunca kullanıldığında bile B.cereus'u öldüremediği, bu çözeltilerden sadece \%3'lük hidrojen peroksit ile 4 saat muamele sonucu bakterinin eradike edilebildiği görülmüştür. Daha önceleri Bacillus türlerinin kontakt lens kullanımına bağlı keratit olguları tanımlanmış olsa da bu olgular kültür ile kanıtlanmamıştır' ${ }^{1}$ Bu raporun Türkiye'den bildirilen ilk B.cereus olgusu olduğu düşünülmektedir. Olguda B.cereus enfeksiyonu için iki 
önemli risk faktörü olan travma ve kontakt lens kullanımı bulunmaktadır. Burada enfeksiyon kaynağı olan kontakt lens, darp esnasında bakteri sporları ile kontamine olabileceği gibi kontaminasyon çevre kaynaklı da olabilir.

B.cereus ürettiği beta laktamazlar sayesinde penisilin ve sefalosporinlere direnç göstermektedir. Klindamisin, eritromisin, kloromfenikol, vankomisin ve aminoglikozidler ise genel olarak bakterinin duyarlı olduğu antibiyotikler$\operatorname{dir}^{17}$. CLSI kriterlerine göre gerçekleştirdiğimiz antibiyotik duyarlılık testinde bakteri, ampisilin ve seftazidime direnç gösterirken siprofloksasin, vankomisin ve imipeneme duyarlı bulunarak literatürle uyumlu sonuçlar elde edilmiştir. Bakteriyel keratitlerin tedavisinde florokinolonlar monoterapide kullanılmaktadır ${ }^{18}$. Bu olguda da ampirik olarak başlanan topikal moksifloksasine devam edilmesi sonucu keratit olgusu tam iyileşme ile sonuçlanmıştır. Bunun d1şında çeşitli çalışmalarda, Bacillus türleri ile gerçekleşen keratitin tedavisinde başarılı olmak için topikal gentamisinin, tek başına ya da diğer antibiyotiklerle kombine halde kullanıldığ 1 rapor edilmiştir ${ }^{19}$. Bunun yan sıra bakteriyel keratit tedavisinde kullanılan antibiyotiklerin karşılaştırıldığı bir çalışmada sefalosporin ve aminoglikozid kombinasyonu ile monoterapide kullanılan florokinolon arasında, tedavi süresi ve etkinlik açısından anlamlı bir fark bulunmadığını belirtmiştir ${ }^{20}$. Bu olguda da topikal moksifloksasin kullanımı ile tedavide başarı sağlanmıştır.

Sonuç olarak, günümüzde kontakt lens kullanımının artış göstermesi ile birlikte kontakt lens kullanımına bağlı bakteriyel keratit olguları da buna paralel olarak artış göstermiştir. Bakteriyel etkenlerin neden olduğu keratit olguları erken tedavi edilmediğinde geri dönüşümsüz görme kayıplarına neden olmaktadır. Bu nedenle, B.cereus ve diğer enfeksiyöz etkenlerin neden olduğu keratit olgularında tedavi en erken sürede ve bakterinin direnç profili göz önünde bulundurularak başlanmalıdır.

\section{Etik Kurul}

Bu çalışmada hasta onamı ile yetinilmiş etik kurula gereksinim duyulmamıştır.

\section{Çıkar Çatışması}

Yazarlar arasında çıkar çatışması bulunmamaktadır. 
J Biotechnol and Strategic Health Res. 2020;4(1):56-60

AYHANCI, ÖLMEZ, KÖROĞLU, ALTINDISş, ALİŞAN, B.cereus Keratiti

\section{Kaynaklar}

1. Pinna A, Sechi LA, Zanetti S, et al. Bacillus cereus Keratitis Associated with Contact Lens Wear. American Academy of Ophthalmology. 2001:108 (10);161-642.

2. Johns Hopkins Center for Health Security, centerforhealthsecurity.org (Son Erișim Tarihi: 15.12.2019)

3. https://wickhamlabs.co.uk/technical-resource-centre/fact-sheet-bacillus-subtilis/(Son Erișim Tarihi: 15.12 .2019 )

4. https://www.selfhacked.com/blog/b-subtilis/ (Son Erișim Tarihi: 15.12.2019)

5. Turhanoğlu NM, Vural DG. Yanıkta izole edilen Bacillus licheniformis. Türk Hijyen ve Deneysel Biyoloji Dergisi. 2016; 73(3): 267 - 270.

6. Kalayl E, Beyatl Y. Bacillus Cinsi Bakterilerin Antimikrobiyal Aktiviteleri, PHB Üretimleri ve Plazmid DNA'lart. Orlab On-Line Mikrobiyoloji Derg. 2003; 12: 4-35.

7. Schnepf E, Crickmore N, Rie JV, et al. Bacillus thuringiensis and its pesticidal crystal proteins. Microbiol. Mol. Biol. Rev. 1998; 62(3):775-806.

8. Hernandez E, Ramisse F, Ducoureau JP, et al. Bacillus thuringiensis subsp. konkunian (serotype H34) superinfection case report and experimental evidence of pathogenicity in immunosuppressed mice. J. Clin. Microbiol. 1998; 36(7):2138-2139.

9. Drobniewski FA. Bacillus cereus and related species. Clin Microbiol Rev. 1993; 6(4):324-38.

10. Demir SÖ, Durmuş MA, Karagenç AÖ, et al. Bacillus cereus’un Etken Olduğu Kateter İlişkili Kan Akımı Enfeksiyonu. Çocuk Dergisi. 2016; 16(1): 39-42

11. Davenport R, Smith C. Panophthalmitis due to an organism of the Bacillus subtilis group. Br J Ophthalmol. 1952;36:389-392.
12. van Bijsterveld OP, Richards RD. Bacillus infections of the cornea. Arch Ophthalmol. 1965;74:91-95.

13. Al-Mujaini A, Al-Kharusi N, Thakral A, et al. Bacterial Keratitis: Perspective on Epidemiology, Clinico-Pathogenesis, Diagnosis and Treatment. SQU Med J. 2009: 9(2);184-195.

14. Bourcier T, Thomas F, Borderie V, et al. Bacterial keratitis: predisposing factors, clinical and microbiological review of 300 cases. J Ophthalmol. 2003;87:834-838.

15. Bottone EJ. Bacillus cereus, a Volatile Human Pathogen. Clinical Microbiology Reviews, Apr. 2010;23(2):382-398.

16. Donzis PB, Mondino BJ, Weissman BA, Bruckner DA. Microbial contamination of contact lens care systems. Am J Ophthalmol 1987;104:325-333.

17. Logan NA, Turnbull PCB. Bacillus and recently derived genera. In: Murray PR, editor-in-chief. Manual of Clinical Microbiology, 7th ed. Washington, DC: American Society for Microbiology, 1999; chap. 23.

18. Güler M, Kurtj, Evren Ö, ve ark. Yöremizdeki Bakteriyel Keratitlerin Klinik ve Mikrobiyolojik Özellikleri. Firat Tip Dergisi. 2008;13(4): 235-238.

19. Tabbara KF, Tarabay N. Bacillus licheniformis corneal ulcer. Am J Ophthalmol. 1979;87:717-719.

20. Karalezli A, Nurözler AB, Telek H, Dumand S. Bakteriyel Keratit Tedavisinde Kullanllan Antibiyotiklerin Etkinliğinin Karșılaştırılması ve Etyolojide Rol Oynayan Faktörler. Turkiye Klinikleri J Ophthalmol 2008;17(4):238-244 